\title{
PEREMAJAAN KAWASAN PASAR BAUNTUNG BANJARBARU (REDEVELOPMENT)
}

\author{
Heldasari \\ Program Studi Teknik Arsitektur Fakultas Teknik Universitas Lambung Mangkurat \\ heldasari55@gmail.com \\ Pakhri Anhar \\ Program Studi Teknik Arsitektur Fakultas Teknik Universitas Lambung Mangkurat \\ pakhrianhar@ulm.ac.id
}

\begin{abstract}
ABSTRAK
Pasar Bauntung Banjarbaru adalah pasar yang telah berdiri sejak tahun 1965 yang hingga kini mengalami peningkatan jumlah pedagang terutama pedagang kaki lima. Pasar ini berlokasi di jalan Lanan, berada tepat di pusat Kota Banjarbaru. Pasar bauntung kini mengalami kemerosotan yang dapat dilihat dari bangunan dan fasilitas di dalamnya yang tidak terjaga. Selain itu akibat meningkatnya pedagang kaki lima maka zonasi dan sirkulasi di pasar ini tidak teratur. Pemecahan permasalahan arsitektur yang tepat untuk Pasar Bauntung Banjarbaru yaitu, peremajaan (redevelopment) Kawasan Pasar Bauntung Banjarbaru yang mewadahi kebutuhan pengguna (pedagang dengan para pembeli) dengan menyesuaikan pada penyelesaian aktivitas pasar subuh, zonasi, dan sirkulasi sehingga dapat menjadikan kawasan pasar yang bersih, aman, dan nyaman. Metode arsitektur programatik untuk mencapai pasar bersih, aman, dan nyaman dengan berfokus pada aktivitas pasar subuh, zonasi, dan sirkulasi menjadi pilihan pendekatan yang digunakan dalam menyelesaikan masalah arsitektur di Pasar Bauntung Banjarbaru. Hal tersebut diwujudkan pada sirkulasi yang tertata sesuai kegunaan, zonasi yang optimal baik diluar maupun di dalamnya, dan aktivitas pasar subuh yang lebih mudah dalam pengelolaannya.
\end{abstract}

Kata Kunci: Pasar Bauntung Banjarbaru, sirkulasi, zonasi

\begin{abstract}
Banjarbaru Bauntung Market is a market that has been established since 1965 which until now has experienced an increase in the number of traders, especially street vendors. This market is located on Jalan Lanan, right in the center of Banjarbaru City. Bauntung market is experiencing a decline which can be seen from the buildings and facilities inside that are not maintained. In addition, due to the increase in street vendors, zoning and circulation in this market are irregular. The right architectural problem solving for the Banjarbaru Bauntung Market, namely, the redevelopment of the Banjarbaru Bauntung Market Area which accommodates the needs of users (traders and buyers) by adjusting the dawn market, activities, zoning, and circulation, as to make a clean, safe, and comfortable market area. Programmatic architectural methods to achieve a clean, safe, and comfortable market by focusing on market activities at dawn, zoning, and circulation are the preferred approaches used in solving architectural problems in the Bauntung Banjarbaru Market. This is manifested in the circulation arranged according to use, optimal zoning both inside and outside, and dawn market activities that are easier to manage.
\end{abstract}

Keyword: Bauntung Market, Banjarbaru, circulation, zoning 


\section{PENDAHULUAN}

Pasar rakyat mempunyai peran yang sangat penting dalam perekonomian masyarakat kalangan menengah kebawah, karena dapat menunjang perekonomian, menghasilkan interaksi, dan sebagai alat yang dipakai (sarana) untuk memenuhi kebutuhan. Kegiatan perekonomian yang terus berlangsung di pasar tersebut, akan menimbulkan terjadinya interaksi antara pedagang dengan pembeli yang menjadi kebiasaan masyarakat berupa sistem tawar menawar pada saat melakukan jual beli barang dagangan.( Oktavina,2011)

Pasar Bauntung merupakan satu-satunya pasar rakyat yang berada di Kota Banjarbaru. Kota Banjarbaru pada awalnya berstatus sebagai kota administratif dibawah Pemerintahan Kabupaten Banjar sehingga Pasar Bauntung berkembang menjadi pasar kecamatan. Seiring berjalannya waktu, status Kota Banjarbaru berubah menjadi Kota Madya yang kemudian pasar dikelola oleh Pemerintah melalui Dinas Perdagangan Kota Banjarbaru dan dipimpin oleh Kepala UPT Pasar Bauntung Banjarbaru. (Fariz, 2018)

Pasar Bauntung Banjarbaru telah ada sejak Lama dengan jumlah pedagang yang masih sedikit. Kemudian, Pasar direnovasi dengan membangun toko-toko dan bak/los karena adanya kebakaran yang menghanguskan hampir sebagian pasar yang dibangun di atas tanah dengan luas \pm $1,5 \mathrm{HA}$. Pembangunan pasar terus berkembang dari bangunan sederhana menjadi permanen dan bertambahnya atap pada salah satu jalan arah barat di area pasar. (Fariz, 2018)

Seiring dengan perkembangan jumlah penduduk yang semakin banyak, maka cakupan layanan pasar menjadi lebih besar dan luas. Namun cakupan layanan pasar tidak diimbangi dengan penambahan sarana/ prasarana yang memenuhi syarat. Hal ini menyebabkan Pasar Bauntung terkesan kumuh, tidak teratur, dan melebihi kapasitas. Jika tidak segera diatasi, maka permasalahan Pasar Bauntung Banjarbaru akan menjadi semakin rumit. (Noor, 2012)

Kondisi Pasar Bauntung Banjarbaru saat ini yang semakin memprihatinkan baik dilihat dari aspek kawasan maupun aspek bangunan, yaitu Jumlah pedagang yang semakin lama semakin bertambah terutama pedagang kaki lima pada subuh hingga pagi hari yang berjualan di pinggir jalan. Kemudian, sirkulasi tercampur antara pejalan kaki, sepeda motor, becak, dan gerobak. Selain itu, Zonasi pasar yang tidak tertata. Sedangkan sampah terlihat oleh para konsumen karena tidak tersedianya pengelolaan sampah yang baik dan kondisi lantai tidak terawat. Yang terakhir parkir tersebar hingga keluar pasar.

Pasar Bauntung mempunyai visi berupa terwujudnya pasar bersih, aman dan nyaman. Agar terwujudnya visi tersebut agak sulit dicapai tanpa adanya penanganan berupa penataan kembali pada pasar ini. Oleh sebab itu, perlu adanya peremajaan yaitu berupa perubahan fisik kawasan (melalui penataan) sebagai akibat perubahan pemanfaatan baik dari segi bangunan, lahan, maupun kawasan. Perubahan pemanfaatan tersebut disebabkan oleh tuntutan kegiatan/aktivitas ekonomi ataupun kekuatan sosial baik dipandang secara kualitas maupun kuantitas sehingga dapat menyelesaikan permasalahan yang ada pada pasar saat ini. (Fariz, 2018)

Adanya rencana pemerintah kota untuk melakukan relokasi pasar rakyat ke Kawasan RO. Ulin tidaklah dapat menghapus eksistensi pasar ini, hanya cakupannya tentu akan lebih kecil (kawasan). Sehingga dengan mempertimbangkan lokasi, sejarah pasar, dan kebutuhan masyarakat yang sudah familiar dengan pasar ini maka solusi program peremajaan yang dipilih adalah redevelopment. Sehingga pasar ini akan tetap berfungsi sebagai pasar dengan cakupan atau lingkup layanan yang lebih kecil (kawasan).

Permasalahan arsitektural yang muncul adalah "bagaimana rancangan peremajaan (redevelopment) Pasar Bauntung Banjarbaru yang mewadahi kebutuhan pengguna (pedagang dengan para pembeli) dengan menyesuaikan pada penyelesaian sirkulasi, aktivitas pasar subuh, dan zonasi yang optimal sehingga dapat menjadikan kawasan pasar yang bersih, aman, dan nyaman". 


\section{TINJAUAN PUSTAKA}

\section{A. Tinjauan Pasar Rakyat}

\section{Pengertian Pasar}

Suatu sistem, tahapan tindakan yang harus dijalankan (prosedur), hubungan sosial, dan semua fasilitas fisik atau non fisik (infrastruktur) yang di dalamnya terdapat kegiatan berupa perekonomian. Kegiatan perekonomian tersebut seperti usaha dengan menjual barang, jasa maupun tenaga kerja bagi seseorang yang membutuhkan dengan diberikan imbalan berupa uang. (Santoso, 2017, pp. 21-68)

\section{Sejarah}

Pasar dikenal dalam lingkungan masyarakat yang bertempat tinggal secara tetap. Secara umum, pasar dapat ditemukan disuatu ruang atau lapangan yang terbuka, baik di bawah pohon besar ataupun disalah satu sudut perempatan jalan, dan bahkan dapat ditemukan di tempat lainnya yang strategis jika dilihat dengan jarak capai dan aksesibilitas dari dalam maupun luar lingkungan tersebut. Awal mulanya pasar hadir pada waktu-waktu tertentu saja, dengan prasarana yang serba sementara. Pasar yang sifatnya hadir pada waktu-waktu tertentu saja dikenal dengan adanya pasar berdasarkan hari/menggunakan nama hari. (Oktaviana, 2011)

Pasar tradisional pada dasarnya berupa kegiatan jual beli berupa barang maupun jasa di antara petani satu dengan petani lainnya, pedagang eceran, dan penduduk lingkungan setempat dengan cara melakukan interaksi maupun tawar menawar barang yang menjadikan sebuah tradisi dengan suasana yang akrab. (Oktaviana, 2011)

Salah satu bentuk pusat perbelanjaan peninggalan zaman Belanda yang ada di kota-kota Indonesia yaitu pasar dengan toko maupun warung disekitarnya (retail). Pasar yang dimaksud seperti area terbuka, bangsal dan los yang memiliki atap atau kombinasi dari area terbuka dilengkapi bangsal dan los beratap. (Oktaviana, 2011)

\section{Fungsi}

Bagi pemakai barang/jasa pasar bertujuan untuk mempermudah menemukan barang dan jasa tersebut. Sedangkan bagi pihak yang melakukan produksi, bertujuan sebagai tempat mempermudah proses penyaluran barang hasil produksinya. Fungsi utama pasar secara umum, yaitu sebagai pembentuk harga, sarana distribusi, dan tempat promosi. (Oktaviana, 2011)

\section{Pelaku}

Pasar tentu terdapat pelaku di dalamnya yang terdiri dari pedagang dan konsumen (pembeli, pengunjung, dan pelanggan). (Oktaviana, 2011)

\section{Ciri}

Pasar Rakyat memiliki ciri yaitu sistem tawar menawar yang dilakukan antara penjual dan pembeli, pedagang berjumlah lebih dari satu yang punya hak atas stand dan hak penuh terhadap barang dagangan disetiap stand masing-masing, terbagi berdasarkan pengelompokan dan jenis barang, serta terbagi berdasarkan tipe tempat jualan. (Oktaviana, 2011)

\section{Tipe}

Salah satu tipe Pasar Rakyat yaitu Tipe A berdasarkan sistem harian dengan jumlah pedagang paling sedikit adalah 400 orang, dan memiliki lahan minimal seluas $5000 \mathrm{~m}^{2}$. (Peraturan Menteri Perdagangan, 2017)

\section{B. Tinjauan Peremajaan Pembangunan Kembali (Redevelopment)}

Peremajaan pembangunan Kembali merupakan suatu upaya dalam melakukan penataan kembali kawasan kota dengan berawal dari melakukan pembongkaran sarana atau prasarana baik sebagian atau seluruh kawasan kota tersebut (unsur lama menjadi unsur kawasan kota yang lebih baru) dengan alasan telah dinyatakan bahwa tidak dapat dipertahankan lagi kehadirannya. $\mathrm{Hal}$ tersebut memiliki tujuan untuk meningkatkan vitalitas serta kualitas dari lingkungan suatu Kawasan. (Martokusumo, 2008)

\section{Tinjauan Konsep}

\section{Konsep Filosofi}

Pasar akan dilakukan peremajaan
dengan cara perubahan total (redevelopment) karena aktivitas pasar subuh, zonasi, dan sirkulasi pasar harus diperbaiki akibat mengalami kemunduran. 
Sehingga pembangunan kembali akan mempermudah rancangan pada pasar ini.

Dengan bangunan yang memiliki satu massa, dimana seluruh aktivitas dilakukan di dalam selain sirkulasi luar bangunan dan parkir. Hal ini, menjadikan pasar terkesan modern dengan tujuan pasar bersih, aman, dan nyaman.

Meskipun di dalam bangunan terkesan modern. Namun, berbeda dengan tampilan bangunan yang terbentuk dari hasil transformasi dari pengaruh bangunan kolonial di Kawasan Banjarbaru.

Modern yang dimaksud disini yaitu pada kondisi yang mengharuskan pasar tetap bersih terutama pada lantai, area dagang, sirkulasi vertikal, dan area lainnya yang dirasa perlu. Selain bersih tentu harus pasti aman dan nyaman. Pada pasar ini sirkulasi dan fasilitas lainnya harus aman terhadap penggunanya serta mudah (nyaman) dalam sirkulasi dan pembagian zona.

Sedangkan untuk aspek historis yaitu dalam implementasi pada ekspresi bangunan dan lingkup pelayanan yang diperkecil dari sebelumnya dikarenakan pasar akan mengalami relokasi yang tentunya dalam lingkup yang lebih besar.

\section{Bentuk dan Tampilan}

Bentuk dan tampilan yang diterapkan pada Pasar Bauntung Banjarbaru adalah arsitektur kolonial yang ada di Kota Banjarbaru. Karena berdasarkan lokasi tapak yang berada di sekitar bangunan kolonial.

Bangunan kolonial pada umumnya yaitu berupa bangunan yang terlihat kokoh, tinggi, memiliki atap datar untuk gedung dan beratap miring untuk perumahan biasa serta memiliki detail-detail tertentu.
Tabel 1. Ciri Bangunan Kolonial di Banjarbaru

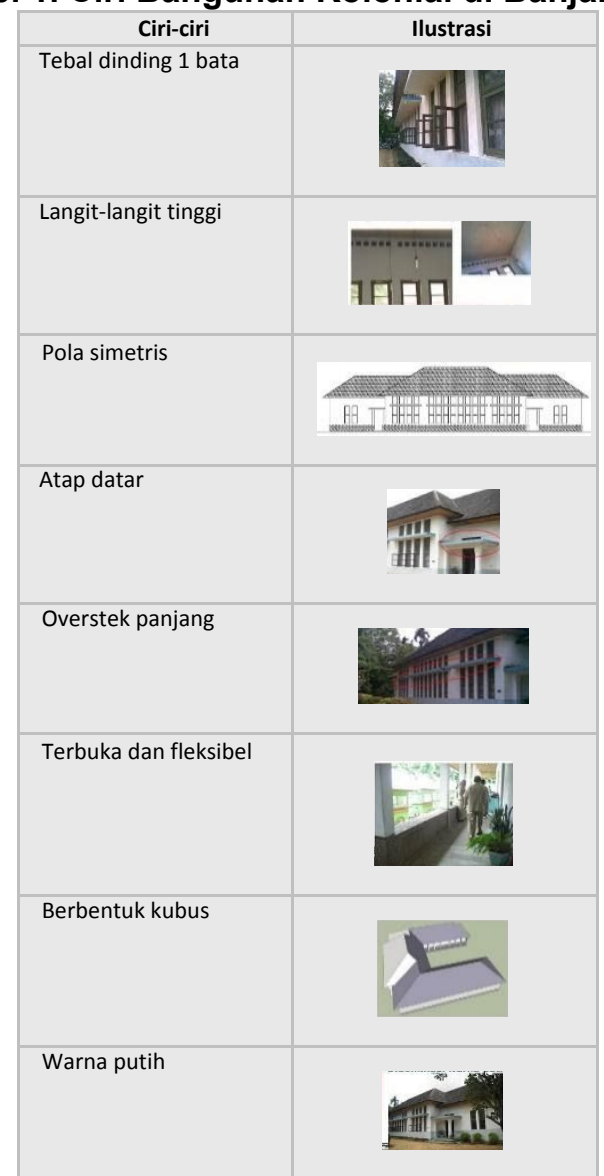

Sumber: (Arsitektur Kolonial pada Bangunan

Pemerintah Kota Banjarbaru, 2016)

\section{Zonasi (Pengelompokan)}

Berdasarkan data yang didapat, Pasar Bauntung Banjarbaru terbagi berdasarkan blok-blok yang diantaranya memiliki ruko sebanyak 27 buah, toko/kios sebanyak 334 buah, dan bak/los sebanyak 248 buah. (Fariz, 2018)

Pedagang yang berada di area bagian tengah, di lantai dua, maupun di ujung tapak terlihat sepi pembeli. Mereka hanya mengharapkan pelanggan setia. Selain itu banyak terdapat toko yang disewakan kembali maupun dalam keadaan tutup. Kebanyakan yang tutup ada di lantai dua, blok sayur, dan blok I. Pada saat dikonfirmasi mereka mengalami penurunan penghasilan karena sangat jarang pengunjung dan pembeli masuk ke area tengah tapak.

Selain itu zonasi yang lama tidak diberlakukan lagi karena banyaknya PKL yang berjualan di jalan pada saat berlangsungnya pasar subuh antara pukul 04.00-09.00. Bahkan kini para PKL ada yang berjualan di siang, sore, bahkan malam hari. 
Sehingga pengaturan zonasi perlu diterapkan kembali.

Pengelompokan pedagang pada Pasar

Bauntung dilakukan berdasarkan jenis dagangan atau jenis komoditi seperti area kering, setengah kering, dan area basah.

Zonasi sebaiknya memiliki sistem yang sangat rapi serta efektif. Hal ini dilakukan untuk memudahkan para pembeli menemukan jenis barang yang dibutuhkan pada pasar ini. Selain itu kios berada di tempat strategis dan memiliki dua muka karena tiap blok terdiri dari dua deret. Jika kios berada paling luar maka tampak depan menghadap keluar agar etalase berfungsi maksimal.

Fasilitas pada pasar seperti ruang dagang berupa los harus dibuat modular (agar lebih cepat, mudah dan efisien) dan toko/kios harus memperhatikan arah angin agar tidak menutupi arah datang dan perginya angin. Selain ruang dagang, berbagai fasilitas umum seperti ATM Center, Pos jaga/keamanan, Klinik, Mushola, Toilet yang terpisah antara laki-laki dan perempuan, dan Ruang bersama untuk kegiatan komunitas pasar. Kemudian adanya kantor pengelola untuk mengelola pasar dengan kondisi ruang yang permanen. Kantor tersebut dapat berada di area pasar atau di luar area pasar dengan syarat mudah dicapai pengelola, pengunjung maupun pedagang pasar.

\section{Tabel 2. KMK No.519 Beberapa persyaratan dalam penataan pasar}

\begin{tabular}{|c|c|c|}
\hline \multicolumn{3}{|l|}{$\begin{array}{l}\text { Area pasar terk } \\
\text { klasifikasinya. }\end{array}$} \\
\hline \\
\hline \multicolumn{3}{|c|}{$\begin{array}{l}\text { Tempat penampungan dan pemotongan memiliki jarak } \\
\text { minimal } 10 \mathrm{~m} \text { atau dapat dibatasi tembok minimal setinggi } 1,5 \\
\mathrm{~m} \text { dengan bangunan pasar utama. }\end{array}$} \\
\hline \multicolumn{3}{|c|}{$\begin{array}{l}\text { Kios yang menghadap keluar sebaiknya non sembako seperti } \\
\text { tekstil dan alat kebutuhan rumah tangga. }\end{array}$} \\
\hline \multicolumn{3}{|c|}{$\begin{array}{l}\text { Los berada ditengah antara toko dan kios, los terdiri dari sayur, } \\
\text { daging, ayam, ikan basah, sembako, dan lain-lain. }\end{array}$} \\
\hline \multicolumn{3}{|c|}{ Lorong pada setiap los lebarnya minimal 1,5 m. } \\
\hline \multicolumn{3}{|c|}{$\begin{array}{l}\text { Los memiliki identitas nomor dan nama pemilik yang mudah } \\
\text { dilihat. }\end{array}$} \\
\hline \multicolumn{3}{|c|}{$\begin{array}{l}\text { Musholla di lokasi strategis dan tidak berdekatan dengan } \\
\text { penjual daging, ikan, maupun penjual unggas hidup. }\end{array}$} \\
\hline \multicolumn{3}{|c|}{$\begin{array}{l}\text { Bongkar muat khusus terpisah dari tempat parkir dan } \\
\text { pengunjung. }\end{array}$} \\
\hline Makanan basah & Makanan kering & \\
\hline $\begin{array}{l}\text { Memiliki } \\
\text { permukaan meja } \\
\text { yang rata dengan } \\
\text { kemiringan yang } \\
\text { cukup agar }\end{array}$ & $\begin{array}{lr}\text { Memiliki } & \text { meja } \\
\text { yang } & \text { mudah } \\
\text { dibersihkan } & \text { dan } \\
\text { permukaan } & \text { yang } \\
\text { rata. } & \end{array}$ & $\begin{array}{lr}\text { Memiliki } & \text { tempat } \\
\text { penyajian } & \\
\text { makanan } & \text { dengan } \\
\text { kondisi } & \text { yang } \\
\text { tertutup, } & \end{array}$ \\
\hline
\end{tabular}

\begin{tabular}{|c|c|c|}
\hline $\begin{array}{l}\text { terhindar dari } \\
\text { genangan air. }\end{array}$ & & $\begin{array}{l}\text { permukaan rata, } \\
\text { dan mudah dalam } \\
\text { melakukan } \\
\text { pembersihan. }\end{array}$ \\
\hline $\begin{array}{l}\text { Meja memiliki } \\
\text { tinggi minimal } 60 \\
\mathrm{~cm} \text { dari lantai } \\
\text { dengan material } \\
\text { terbuat dari } \\
\text { bahan tahan karat } \\
\text { selain kayu. }\end{array}$ & $\begin{array}{l}\text { Meja memiliki } \\
\text { tinggi minimal } 60 \\
\mathrm{~cm} \text {. }\end{array}$ & $\begin{array}{l}\text { Meja memiliki } \\
\text { tinggi minimal } 60 \\
\mathrm{~cm} .\end{array}$ \\
\hline $\begin{array}{l}\text { Memiliki tempat } \\
\text { pencucian yang } \\
\text { digunakan untuk } \\
\text { bahan dagangan } \\
\text { dan peralatan. }\end{array}$ & $\begin{array}{l}\text { Tempat untuk } \\
\text { mencuci tangan } \\
\text { dilengkapi dengan } \\
\text { sabun dan air } \\
\text { yang dapat } \\
\text { mengalir. }\end{array}$ & $\begin{array}{l}\text { Tempat cuci tidak } \\
\text { melewati area } \\
\text { perdagangan }\end{array}$ \\
\hline
\end{tabular}

\section{Sumber: (Kesrem, 2017)}

\section{Sirkulasi}

Penataan sirkulasi yang berdasarkan hierarki diantaranya yaitu pejalan kaki, kendaraan roda dua, mobil, mobil pengangkut sampah, becak, gerobak barang, gerobak sampah.

\section{Tabel 3. Penataan Sirkulasi}

Jalur sirkulasi pejalan kaki berdasarkan pertimbangan kebutuhan orang agar dalam bergerak menjadi aman dan nyaman. Permukaan jalur sirkulasi diharapkan kuat dan stabil, tahan terhadap cuaca, memiliki tekstur yang halus, dan tidak licin saat dilewati. Jika terdapat sambungan ataupun gundukan maka tingginya maksimal $1,25 \mathrm{~cm}$.

Jalur pedestrian memiliki lebar minimal $120 \mathrm{~cm}$ dan harus bebas dari tiang (rambu-rambu), pepohonan, perlengkapan jalan yang menghalangi ataupun benda lainnya.

Ramp dengan kemiringan, maksimal $7^{\circ}$ dan pada tiap jarak $9 \mathrm{~m}$ terdapat pemberhentian sebagai tempat istirahat.

Banyak terdapat akses (keluar masuk) sehingga sirkulasi menjadi lebih lancar. Selain itu, semua area dapat terjangkau dengan mudah.

Jalur sirkulasi mudah diakses oleh seluruh konsumen dan tidak menyebabkan penumpukan orang pada satu lokasi.

Koridor terbagi menjadi dua yaitu koridor utama untuk akses langsung dari luar pasar menuju area toko/kios dengan lebar yang ideal adalah 2-3 meter. Sedangkan koridor penghubung menjadi koridor kedua yang menghubungkan antar kios dengan memiliki lebar minimal $180 \mathrm{~cm}$.

Koridor tersebut harus memberikan kemudahan dalam melakukan kegiatan jual beli terhadap sirkulasi pedagang dan pembeli maupun penyandang cacat. Selain itu koridor harus memberikan kemudahan untuk keluar masuk barang dari area bongkar muat ke toko/kios, lapak, dan los. 
Tersedia jalan mengelilingi area pasar dengan lebar minimal $5 \mathrm{~m}$ agar seluruh tempat memberi kesan tampak bagian depan yang dapat diakses melalui segala arah, mencerminkan pemerataan distribusi aktivitas perdagangan, nilai strategis menjadi lebih meningkatkan, lebih mudah untuk melakukan penanggulangan bahaya kebakaran, arus kendaraan dan bongkar muat di dalam pasar jadi lancar dan semakin mudah.

Sumber: (Kesrem, 2017)

\section{METODE PERANCANGAN}

\section{A. Metode Programatik}

Lima Langkah Penyusunan program menurut William Pena (1995) yang diterapkan ke Pasar ini, yaitu tujuan dengan merancang berdasarkan perbaikan kondisi fisik yang meliputi bangunan pasar serta sirkulasi, parkir, dan zonasi khususnya untuk pasar subuh yang ada di Pasar Bauntung dengan cara redevelopment (pembangunan kembali). Sehingga pasar bersih, aman, dan nyaman terpenuhi.

Selanjutnya, fakta dengan melakukan tinjauan teori dan studi kasus yang berhubungan dengan pasar, survei mengenai tapak, fungsi, ruang dan bentuk, konsep yang menyesuaikan dengan lingkungan dan fasilitas yang lebih modern.

$$
\text { Kemudian, konsep dengan }
$$

pertimbangan keberadaan pasar yang terletak di pusat Kota Banjarbaru dan dikelilingi bangunan arsitektur kolonial sebagai kota yang pernah dirancang (memiliki nilai sejarah). Maka rancangan Pasar Bauntung akan menyesuaikan lingkungan sekitar dengan fasilitas yang lebih modern.

Setelah itu, tentukan kebutuhan dengan pengelompokan data pedagang, yaitu kelompok kering, kelompok basah, sayur, rempah-rempah dan sebagainya. Maka, nyatakan masalah dari tahapan yang telah didapat.

\section{PEMBAHASAN}

\section{A. Konsep Desain}

\section{Aktivitas Pasar Subuh}

Tersedia area untuk pasar subuh di dalam bangunan yang dilengkapi dengan tempat dagang sesuai jenis komoditi serta penanda yang tertata dan jelas agar lebih mudah dalam mengelola aktivitas pasar subuh.

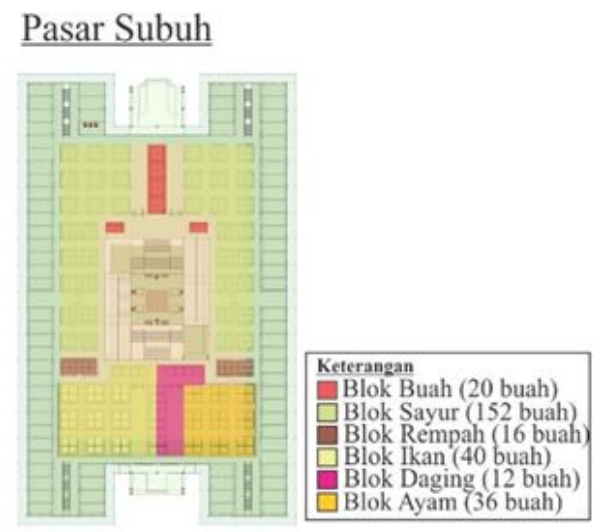

Gambar 1. Pasar Subuh

\section{Zonasi}

Perlunya zonasi yang optimal pada pasar ini. Oleh karena itu, di luar bangunan perlu adanya area servis (untuk ruang genset, rumah kompos, dan tempat sampah), area parkir (mobil, kendaraan roda dua, dan area parkir bongkar muat). Sedangkan di dalam bangunan, lokasi pedagang sesuai jenis komoditi yang telah disediakan dengan dilengkapi penanda. Hal ini, membuat massa bangunan memang harus di bangun kembali sehingga sesuai dengan permasalahan yang ada.

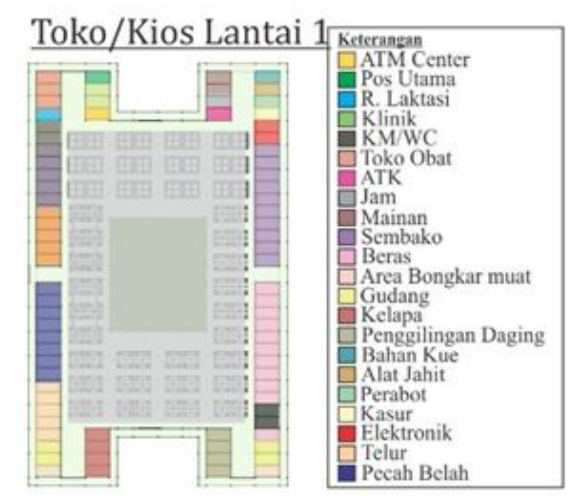

Gambar 2. Toko/kios Lantai 1

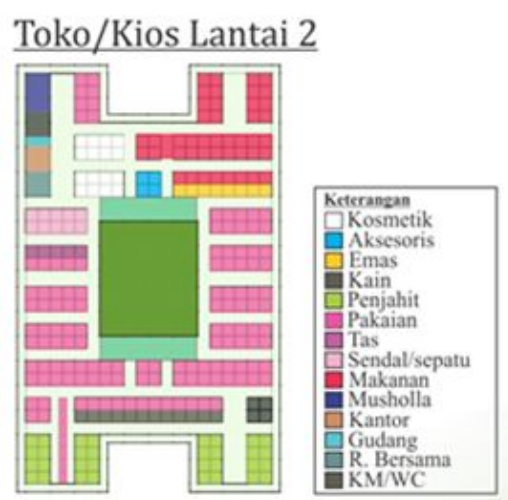

Gambar 3. Toko/kios Lantai 2 


\section{Sirkulasi}

Sirkulasi pada pasar ini berbeda antara mobil, kendaraan roda dua, pejalan kaki, mobil bak, becak, gerobak, dan mobil pengangkut sampah yang dilengkapi fasilitas seperti tempat istirahat berupa bangku, area parkir, Lampu, dan penanda.

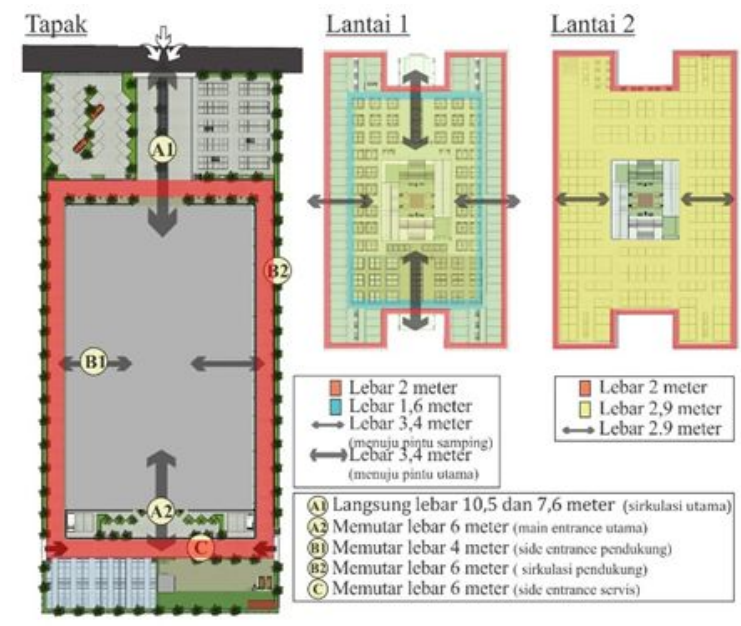

Gambar 4. Sirkulasi

\section{B. Hasil Rancangan}

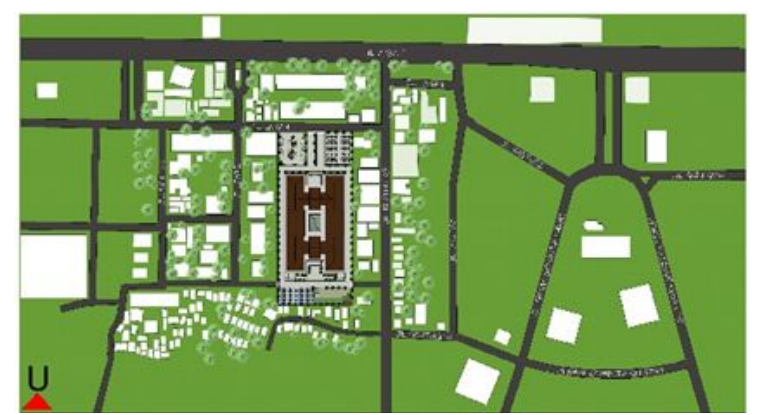

Gambar 5. Situasi

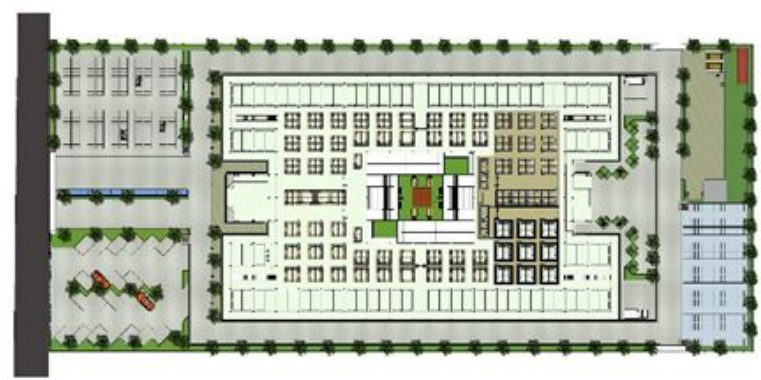

Gambar 6. Rencana Tapak

Sekeliling kawasan Pasar diberikan pagar berupa panel yang bertujuan untuk menghalangi pemandangan dari dalam atau luar bangunan.

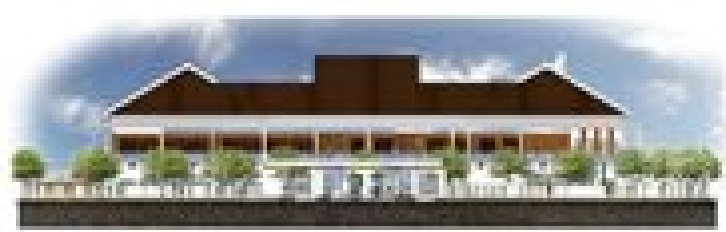

Gambar 7. Tampak Depan Kawasan

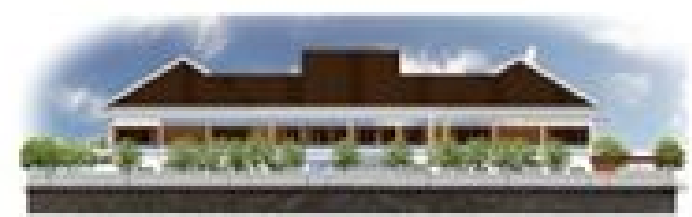

Gambar 8. Tampak Belakang Kawasan

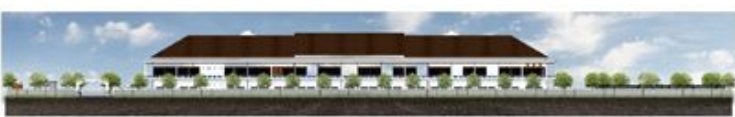

Gambar 9. Tampak Samping Kiri Kawasan

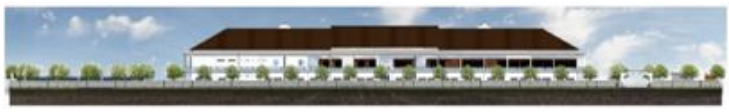

Gambar 10. Tampak Samping Kanan Kawasan

Setiap lantai pada bangunan pasar ini memiliki tinggi $4.20 \mathrm{~m}^{2}$. Kemudian struktur atap menggunakan baja ringan dengan penutup atap alderon, spandek transparan, dan dak. Selanjutnya, pondasi yang digunakan yaitu pondasi telapak.

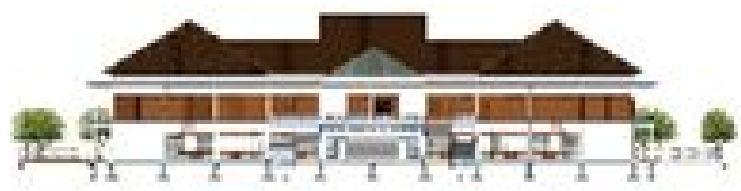

Gambar 11. Potongan Kawasan

Pagar yang terdapat di lantai dua memiliki tinggi $80 \mathrm{~cm}$ dengan menggunakan material besi hollow dan kaca.

Ruang toko/kios yang berada di lantai dua memiliki ukuran dengan luasan $3 \times 3 \mathrm{~m}^{2}$ dan tingginya $3 \mathrm{~m}$ dari muka lantai. Ruang tersebut menggunakan material kayu papan dengan rangka besi hollow.
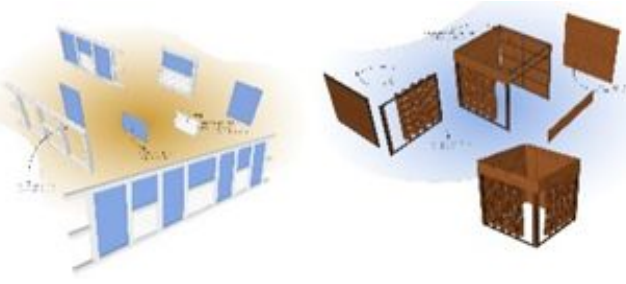

Gambar 12. Detail Arsitektural

Area pejalan kaki terdapat kantilever yang dilengkapi tempat untuk pengumuman 
seperti zonasi pasar ataupun sarana promosi yang dapat dilihat para pejalan kaki.

Selain itu, terdapat tempat sampah yang terdapat di Kawasan pasar, lampu dilengkapi tempat sebagai media promosi, dan pot tanaman di area luar bangunan.

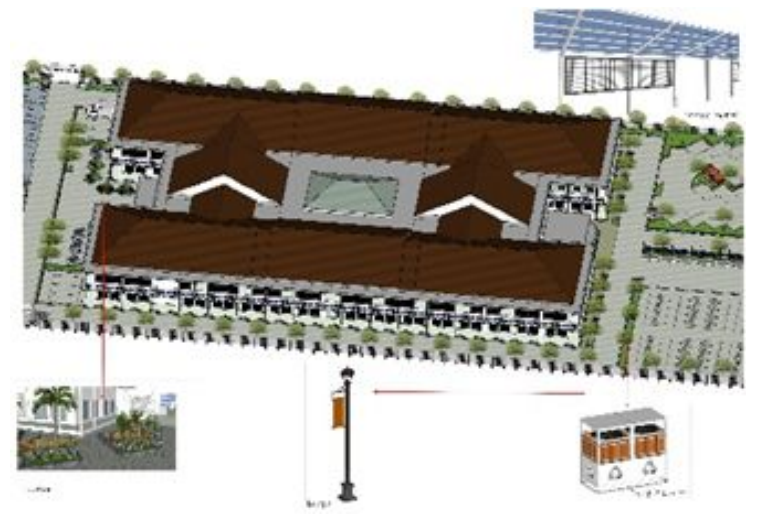

Gambar 13. Detail Lansekap

Area hijau berfungsi sebagai tempat untuk menunggu maupun beristirahat bagi para pembeli yang dilengkapi tempat duduk.

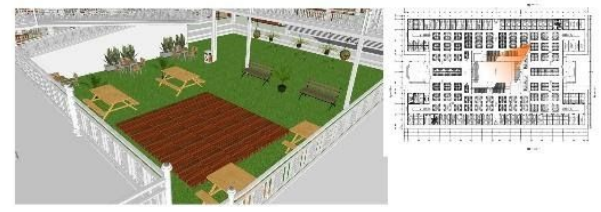

Gambar 14. Perspektif Area Hijau

Area sayur memiliki tinggi $3 \mathrm{~m}$ dengan ukuran $2 \times 2 \mathrm{~m}^{2}$. Setiap ruang dagang menggunakan material kayu papan dan besi hollow.

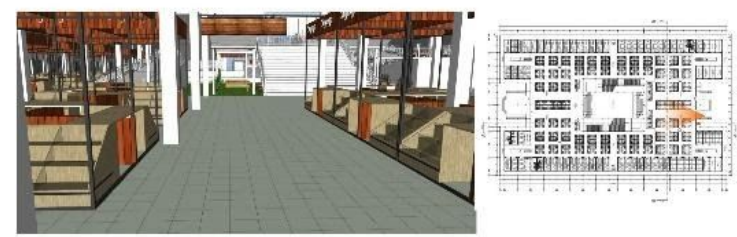

Gambar 15. Perspektif Area Sayur

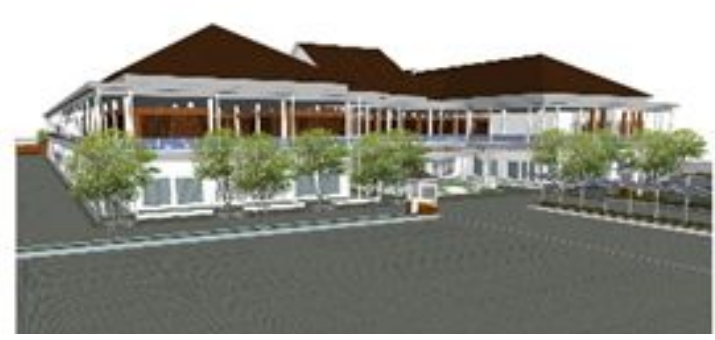

Gambar 16. Perspektif Depan Bangunan

\section{KESIMPULAN}

Menjadikan Pasar lebih bersih, aman, dan nyaman dengan cara peremajaan (redevelopment) kawasan Pasar Bauntung Banjarbaru yang mewadahi kebutuhan pengguna (pedagang dengan para pembeli). Peremajaan berfokus pada sirkulasi melalui hierarki antara pejalan kaki dan pengguna lainnya, zonasi agar dapat menentukan tata letak ruang maupun pengaturan luasan kios/toko, dan aktivitas pasar subuh yang berlangsung di dalam bangunan sehingga bangunan, parkir dan sirkulasi khusus pasar subuh akan berbeda dari sebelumnya.

\section{DAFTAR PUSTAKA}

Arsitektur Kolonial pada Bangunan Pemerintah Kota Banjarbaru. (2016, February 7)

Dharma, A. (1998). Seri Diktat Kuliah: Teori Arsitektur 2. Jakarta: Gunadarma

Fariz, A. (2018, Februari 9). Bab IV (Skripsi) Peranan Penerimaan Pajak Retribusi Dalam Meningkatkan Pajak Asli Daerah Di Uptd Pasar Banjarbaru

Kesrem, T. (2017, Mei 18). KMK No. 519 ttg Pedoman Penyelenggaraan Pasar Sehat.

Laitte, A. (2017, Maret 22). Buku Putih Pasar Tradisional

Martokusumo, W. (2008). Revitalisasi, Sebuah Pendekatan dalam Peremajaan Kawasan, Vol.19 No.3, 57-73

Oktavina, galuh. (2011). Redesain Pasar Tradisional Jongke.Surakarta

Peraturan Menteri Perdagangan. (2017). Peraturan Menteri Perdagangan Republik Indonesia Nomor 37/M-DAG/PER/5/2017 Tentang Pedoman Pembangunan dan Pengelolaan Sarana Perdagangan

Primawardani, Y (2018), Peremajaan dan Pengembangan Wilayah Perkotaan Melalui Penggusuran Ditinjau dalam Perspektif Hak Asasi Manusia Di Kota Surabaya, Vol.9 No.1, 51-68

Santoso,T.M. (2017). Revitalisasi Pasar Johar Semarang dengan Pendekatan Arsitektur Indische (S1 thesis). (pp. 21-68).UAJY

Wahyuni, S. (n.d.). Aplikasi Metode Pemrograman William M Pena. 